\title{
PENGARUH PENDEKATAN KETERAMPILAN PROSES TERHADAP HASIL BELAJAR BIOLOGI PADA POKOK BAHASAN KLASIFIKASI MAKHLUK HIDUP DI KELAS VII SMP TUNAS BARU BATAM
}

\section{AN EFFECT OF PROCESS SKILLS APPROACH TOWARD BIOLOGICAL LEARNING OUTCOMES FOR LIVING CREATURES CLASSIFICATION MATERIAL AT CLASS VII SMP TUNAS BARU BATAM}

\author{
Revida Pinem ${ }^{1}$, Nurhaty Purnama Sari*², Ramses Ramses ${ }^{2}$ \\ ${ }^{1,2,3}$ Program Studi Pendidikan Biologi, FKIP, Universitas Riau Kepulauan, Batam \\ *Koresponden: nurhatipurnamasari@gmail.com
}

\begin{abstract}
Abstrak
Tujuan penelitian adalah untuk mengetahui apakah penerapan pendekatan proses keterampilan dapat memberikan pengaruh terhadap hasil belajar biologi siswa kelas VII pada SMP Tunas Baru, dengan materi Klasifikasi Mahluk Hidup. Jumlah siswa yang mengikuti penelitian sebanyak 165 siswa dari total 5 kelas. Sampel diambil dari kelas VII C (XI) dengan perlakuan menggunakan pendekatan pembelajaran ketrampilan proses dan kelas VII D (X2) dengan menggunakan pendekatan konvensional. Peralatan yang digunakan untuk mengumpulkan data adalah tes dalam bentuk pilihan ganda 25 pertanyaan dengan teknik analisis data menggunakan Uji T tingkat $\alpha=5 \%$. Hasil penelitian rerata nilai post-test XI $=81.00$ dan post test $\mathrm{X} 2=70,45$ dengan hasil Uji $\mathrm{T}$ menunjukkan bahwa $\mathrm{T}_{\text {hitung }}=5,44>\mathrm{T}_{\text {tabel }}=2,00$ sehingga hipotesis nol $\left(\mathrm{H}_{0}\right)$ ditolak dan hipotesis alternatif diterima $\left(\mathrm{H}_{1}\right)$. Ada perbedaan yang signifikan nilai ratarata hasil belajar antara siswa yang dilakukan menggunakan pendekatan ketrampilan proses dengan pendekatan konvensional.
\end{abstract}

Kata Kunci: Ketrampilan Proses, Pembelajaran Konvesional, Hasil Belajar

\begin{abstract}
The research objective was to determine whether the application of process skills approach give impact toward biology learning outcomes at class VII SMP Tunas Baru, for living creature cclassification material. The number of students who took part in the study was 165 students from five classes. Samples were taken from class VII C (XI), they got treatment by using process skills learning approach and class VII D (X2) by using conventional approach. The instrument used to collect data was multiple-choice test consisting 25 questions with data analysis techniques using T test at level $\alpha=5 \%$. The mean of results was XI post-test $=81.00$ and X2 post-test $=70.45$, by using T test results showed that $T_{\text {count }}=5.44>T_{\text {tabel }}=2.00$ so that the null hypothesis $\left(H_{0}\right)$ was rejected and alternative hypothesis $\left(H_{1}\right)$ was accepted. It means that there is a significant difference of students' learning outcomes value average by using process skills approach from conventional approach.
\end{abstract}

Keywords: Process Skills, Conventional Learning, Learning Outcomes

\section{PENDAHULUAN}

Dalam proses pembelajaran terdapat beberapa komponen, dua diantaranya adalah guru dan siswa.Agar proses pembelajaran berhasil, guru harus aktif diantaranya dalam hal mendorong siswa untuk aktif belajar dan memberikan pengalaman belajar yang memadai dengan menggunakan metode - metode pembelajaran yang sesuai 
dengan materi yang diajarkan kepada siswa. Menurut Sutikino, (2004) dalam Fathurahman (2007 ), mengartikan belajar adalah suatu proses usaha yang dilakukan oleh seseorang untuk memperoleh suatu perubahan yang baru sebagai hasil pengalamannya sendiri dalam intraksi dengan lingkunganya. Dalam kemampuan aktivitas siswa dan ketermpilan proses sains bagi siswa SMP di arahkan pada keterampilan proses sains akan membentuk karakter siswa dengan sikap ilmiah kemampuan berpikir dan bertindak kritis baik selama pembelajaran maupun dalam konteks sehari- hari.

Kegiatan pembelajaran ini akan menjadi bermakna bagi peserta didik jika dilakukan dalam lingkungan yang nyaman dan memberikan rasa aman bagi peserta didik. Pembelajaran pada dasarnya merupakan suatu usaha untuk menciptakan kondisi atau system lingkungan yang mendukung dan memungkinkan berlangsungnya proses belajar, kalau belajar dikatakan kegiatan peserta didik maka pembelajaran itu sendiri merupakan kegiatan guru sebagi konsekuensi, karena hanya menerima informasi atau pengetahuan yang diberikan oleh guru atau pendidiknya.

Berdasarkan hasil wawancara yang telah dilakukan dengan guru bidang studi Biologi SMP Tunas Baru kelas VII bahwa yang menjadi kesulitan siswa dalam pokok bahasan klasifikasi makhluk hidup adalah siswa kurang mampu dalam memahami dan menjawab soal pada materi tentang klasifikasi makhluk hidup karena diduga siswa kurang mampu dalam berpikir memahami secara proses (Data nilai mata pelajaran IPA semester I - tabel 1). Berdasarkan uraian maka dikemukakan tujuan penelitian adalah sebagai untuk membuktikan adanya pengaruh dari pelaksanaan Pendekatan Keterampilan Proses Terhadap Hasil Belajar Biologi Siswa Kelas VII Di SMP Tunas Baru Batam 2012/2013.

Tabel 1 . Nilai Akhir kelas VII Pelajaran IPA Semester I

\begin{tabular}{lllll}
\hline Kelas & Jumlah siswa & Nilai Rata-rata & Diatas Rata-rata & Dibawah Rata-rata \\
\hline VII C & 33 & 60 & $65 \%$ & $35 \%$ \\
VII D & 33 & 55 & $50 \%$ & $50 \%$ \\
\hline
\end{tabular}

( Sumber : Guru SMP Tunas Baru Batam)

\section{METODOLOGI}

Jenis penelitian ini bersifat eksperimen. Dalam penelitian ini siswa di bagi dalam dua kelas, yaitu kelas eksperimen dan kelas kontrol. Pada kelas eksperimen 
menggunakan pendekatan proses, sedangkan pada kelas kontrol menggunakan pendekatan konvensional. Penelitian ini dilakukan mulai bulan maret sampai bulan mei 2013 di SMP Tunas Baru Batam. Sampel dalam penelitian ini diambil dari populasi yang pengambilannya menggunakan teknik random sampling sederhana. Sampel digunakan oleh peneliti adalah siswa kelas VII-C sebagai kelas eksperimen dan kelas VII-D sebagai kelas kontrol. Data yang digunakan adalah data primer yaitu : data hasil belajar siswa yang diperoleh dari hasil test akhir setelah penelitian dilaksanakan. Data yang diperoleh secara langsung dari sampel. Sumber data dalam penelitian ini adalah siswa kelas VII-C sebagai kelas eksperimen dan kelas VII- D sebagai kelas kontrol.

\section{PEMBAHASAN}

Berdasarkan hasil analisis jawaban siswa pada kegiatan tes akhir diperoleh data nilai rata- rata hasil belajar siswa yang terlihat pada tabel sebagai berikut:

Tabel 2. Nilai rata- rata simpangan baku dan varians kelas eksperimen dan kelas kontrol

\begin{tabular}{llllc}
\hline Kelas & $\mathrm{N}$ & $\overline{\mathrm{X}}$ & $\mathrm{S}$ & $\mathrm{S}^{2}$ \\
\hline Eksperimen & 33 & 81 & 71,826 & 51,59 \\
\hline Kontrol & 33 & 70 & 80,5052 & 72,34 \\
\hline
\end{tabular}

Berdasarkan pada tabel 2 dapat dilihat bahwa hasil belajar siswa pada kelas eksperimen yang diberi perlakuan dengan pemberian pendekatan keterampilan proses memiliki nilai rata- rata yang lebih tinggi dari hasil belajar siswa pada kelas kontrol.

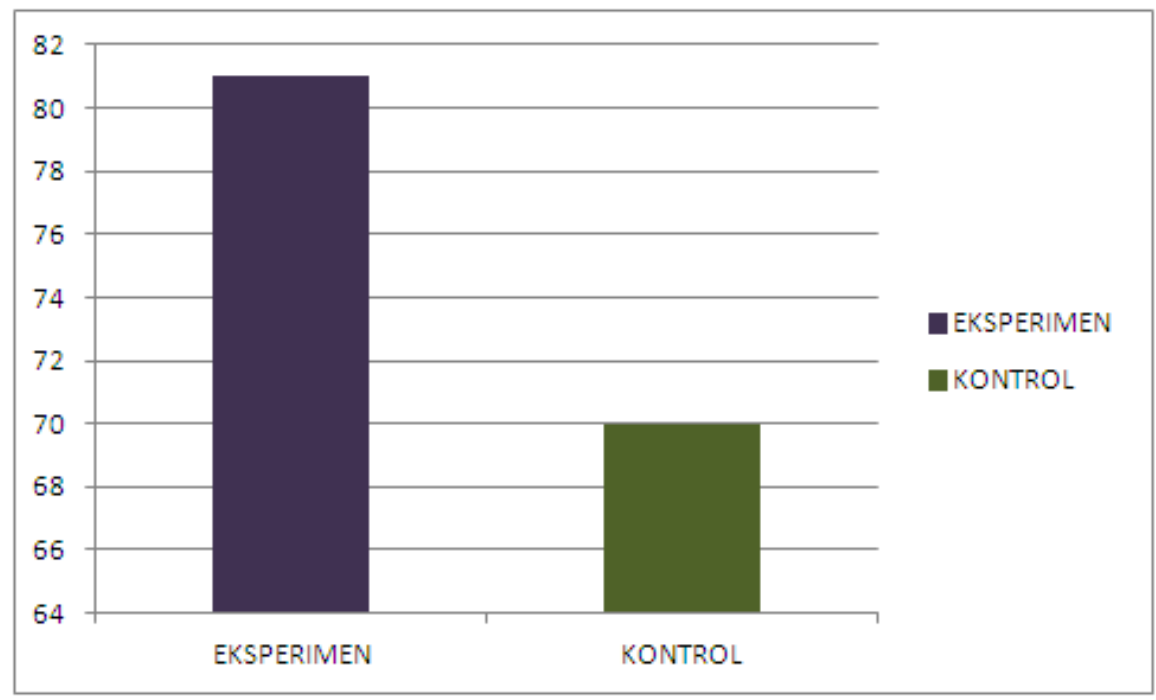

Gambar 2. Histogram Nilai Hasil Belajar Biologi Siswa dengan Menggunakan Pendekatan Proses. 
Untuk dapat menarik suatu kesimpulan dapat dilakukan pengujian dengan uji normalitas, uji homogenitas kemudian dilanjutkan dengan uji hipotesis untuk menentukan statistik mana yang akan digunakan. Dalam hal ini, tingginya pencapaian prestasi belajar siswa dimungkinkan karena dengan proses pembelajaran pada kelas yang menggunakan Pendekatan Proses (X1) memberikan kesempatan pada seluruh siswa untuk terlibat secara aktif dalam mengemukakan pendapatnya sesuai dengan aturan yang berlaku dalam proses pembelajaran dengan menggunakan Pendekatan Proses. Berdasarkan analisis nilai akhir siswa kelas VII memperlihatkan sampel yang homogen dengan data yang berdistribusi normal dan memiliki varians yang tidak berbeda secara signifikan. Keadaan ini menunjukkan bahwa sebelum diberi perlakuan kedua sampel memiliki kemampuan awal yang sama sehingga kelas eksperimen (Kelas VII C/X1 ) dapat diberikan perlakuan yaitu dengan menerapkan pendekatan keterampilan proses, sedangkan dikelas kontrol (Kelas VII D/X2) menggunakan metode konvensional (Metode ceramah). Pengujian hipotesis digunakan uji t. (Tabel 3)

Tabel 3. Hasil Uji Perbedaan Dua Rata-rata Test Akhir

\begin{tabular}{lccl}
\hline Kelas & $\mathrm{T}_{\text {hitung }}$ & $\mathrm{t}_{\text {tabel }}$ & Kesimpulan \\
\hline $\begin{array}{l}\text { Eksperimen } \\
\text { Kontrol }\end{array}$ & 5.438 & 2.02 & Diterima \\
\hline
\end{tabular}

Dari hasil perhitungan $t_{\text {hitung }}>t_{\text {tabel }}$ maka dapat dikatakan bahwa hipotesis $H_{a}$ diterima. Dapat disimpulkan bahwa terdapat pengaruh yang positip pendekatan keterampilan proses terhadap hasil belajar pada kelas eksperimen.

\section{KESIMPULAN}

Dengan melakukan analisi uji $t$ dua pihak sehingga diperoleh $t_{\text {hitung }}=5,438$ dan $t_{\text {tabel }}=2.02$ atau $t_{\text {hitung }}>t_{\text {tabel }}$ maka hipotesis diterima. Sehingga disimpulkan bahwa terdapat perbedaan hasil belajar siswa antara kelas eksperimen yang diberi model pembelajaran pendekatan keterampilan proses dan pada kelas kontrol hanya menggunakan model konvensional dan model pendekatan keterampilan proses baik dalam meningkatkan hasil belajar biologi 


\section{REFERENSI}

Ade Sanjaya, 2010. Pendekatan Keterampilan Proses. Bumi Aksara, Bandung.

Ali, 2002. Kemajuan Bidang IPA. Alfa Beta, Pontianak.

Jackson, 2011. Sismatika Dalam Belajar. Bumi Putra, Jakarta.

Joyce, 2001. Pembelajaran mengarah kepada desain untuk membantu peserta didik. Media Grup, Jakarta.

Muhsan. 2004. Hasil Belajar Biologi. Alfa Beta, Jakarta.

Semiawan. 2009. Pendekatan keterampilan proses dalam Pembelajaran. Rineka Cipta.

Slavin. 2009. Belajar Dan Pembelajaran. Alfa Beta, Pontianak.

Sudjana. 2004. Hasil Belajar Biologi. Alfa Beta, Pontianak.

Sukarno. 2001. Cara Berpikir Dalam Pembelajaran IPA. Rineka Cipta, Jakarta. 